\title{
S100A12 Is Associated with Response to Therapy in Juvenile Idiopathic Arthritis
}

\author{
Faekah Gohar, Janneke Anink, Halima Moncrieffe, Lisette W.A. Van Suijlekom-Smit, \\ Femke H.M. Prince, Marion A.J. van Rossum, Koert M. Dolman, Esther P.A.H. Hoppenreijs, \\ Rebecca ten Cate, Simona Ursu, Lucy R. Wedderburn, Gerd Horneff, Michael Frosch, \\ Dirk Foell, and Dirk Holzinger
}

\begin{abstract}
Objective. Around one-third of patients with juvenile idiopathic arthritis (JIA) fail to respond to first-line methotrexate (MTX) or anti-tumor necrosis factor (TNF) therapy, with even fewer achieving $\geq$ American College of Rheumatology Pediatric 70\% criteria for response (ACRpedi70), though individual responses cannot yet be accurately predicted. Because change in serum S100-protein myeloid-related protein complex 8/14 (MRP8/14) is associated with therapeutic response, we tested granulocyte-specific S100-protein S100A12 as a potential biomarker for treatment response.

Methods. S100A12 serum concentration was determined by ELISA in patients treated with MTX $(n=75)$ and anti-TNF $(n=88)$ at baseline and followup. Treatment response ( $\geq$ ACRpedi50 score), achievement of inactive disease, and improvement in Juvenile Arthritis Disease Activity Score (JADAS)-10 score were recorded.

Results. Baseline S100A12 concentration was measured in patients treated with anti-TNF [etanercept $\mathrm{n}=81$, adalimumab $\mathrm{n}=7$; median 200, interquartile range (IQR) $133-440 \mathrm{ng} / \mathrm{ml}$ ] and MTX (median 220 , IQR $100-440 \mathrm{ng} / \mathrm{ml})$. Of the patients in the anti-TNF therapy group, 74 (84\%) were also receiving MTX. Responders to MTX $(n=57 / 75)$ and anti-TNF $(n=66 / 88)$ therapy had higher baseline S100A12 concentration compared to nonresponders: median 240 (IQR 125-615) ng/ml versus 150 (IQR 87-233) ng/ml, p = 0.021 for MTX, and median 308 (IQR 150-624) ng/ml versus 151 (IQR 83-201) $\mathrm{ng} / \mathrm{ml}, \mathrm{p}=0.002$, for anti-TNF therapy. Followup S100A12 could be measured in 44/75 MTX-treated patients (34/44 responders) and 39/88 anti-TNF-treated patients (26/39 responders). Responders had significantly reduced S100A12 concentration (MTX: $p=0.031$, anti-TNF: $p<0.001$ ) at followup versus baseline. Baseline serum S100A12 in both univariate and multivariate regression models for anti-TNF therapy and univariate analysis alone for MTX therapy was significantly associated with change in JADAS-10.

Conclusion. Responders to MTX or anti-TNF treatment can be identified by higher pretreatment S100A12 serum concentration levels. (First Release January 15 2018; J Rheumatol 2018;45:547-54; doi:10.3899/jrheum.170438)
\end{abstract}

Key Indexing Terms:

JUVENILE IDIOPATHIC ARTHRITIS

BIOLOGICAL THERAPY

BIOLOGICAL MARKERS

PEDIATRIC RHEUMATIC DISEASES

Children's and Adolescents' Hospital, Datteln; Klinik für Kinderheilkunde III, Zentrum für Kinder- und Jugendmedizin, Universitätsklinikum Essen, Essen, Germany.

F.G. was supported by the European Union Seventh Framework Programme (FP7) EUTRAIN (ref.289903) grant. L.W. is supported by the Great Ormond Street Hospital Children's Charity. D.H. and D.F. were funded by the Interdisciplinary Centre of Clinical Research at the University of Münster (IZKF CRA04) and received an unconditional grant from Pfizer Germany for this study. H.M. was supported in part by the US National Institutes of Health (NIH) Grant Award Nos. P30 AR070549, R01 HD089928, U01 AI130830. The content is solely the responsibility of the author and does not necessarily represent the official views of the NIH. The $A B C$ register is maintained with unconditional support from the Dutch Board of Health Insurances (2003-2006), Pfizer, and AbbVie. The BIKeR Registry is supported by an unconditional grant from Pfizer Germany and also the FP7 grant, EC-GA 305266 MIAMI. The CHARMS study was funded by SPARKS UK (08ICH09), the Big Lottery Fund UK (RG/1/010135231), UK Medicines for Children Research Network (NIHR-funded), and NIHR GOS BRC.

F. Gohar, MD, Department of Pediatric Rheumatology and Immunology,

Personal non-commercial use only. The Journal of Rheumatology Copyright @ 2018 . All rights reserved. 
University Children's Hospital Münster; J. Anink, MD, PhD, Department of Pediatrics/Pediatric Rheumatology, Erasmus MC Sophia Children's Hospital Rotterdam; H. Moncrieffe, PhD, Center for Autoimmune Genomics and Etiology, Cincinnati Children's Hospital Medical Center, and Department of Pediatrics, University of Cincinnati; L.W. Van Suijlekom-Smit, MD, PhD, Department of Pediatrics/Pediatric Rheumatology, Erasmus MC Sophia Children's Hospital Rotterdam; F.H. Prince, MD, PhD, Department of Pediatrics/Pediatric Rheumatology, Erasmus MC Sophia Children's Hospital Rotterdam; M.A. van Rossum, MD, PhD, Emma Children's Hospital, Academic Medical Centre and Amsterdam Rheumatology and Immunology Centre, Reade location, Jan van Breemen Institute; K.M. Dolman, MD, PhD, Department of Pediatrics/Pediatric Rheumatology, Onze Lieve Vrouwe Gasthuis; E.P. Hoppenreijs, MD, Department of Pediatrics/Pediatric Rheumatology, St. Maartenskliniek and Radboud University Medical Centre; R. ten Cate, $M D, P h D$, Leiden University Medical Centre; S. Ursu, PhD, School of Biological Sciences, Royal Holloway, University of London

L.R. Wedderburn, $M D, P h D$, Infection, Immunity, Inflammation Programme, UCL GOS Institute of Child Health, UCL; G. Horneff, MD, Centre of Pediatric Rheumatology, Department of General Pediatrics, Asklepios Clinic Sankt Augustin; M. Frosch, MD, German Pediatric Pain Centre, Children's and Adolescents' Hospital; D. Foell, MD, Department of Paediatric Rheumatology and Immunology, University Children's Hospital Münster; D. Holzinger, MD, Department of Paediatric Rheumatology and Immunology, University Children's Hospital Münster, and Klinik für Kinderheilkunde III, Zentrum für Kinder- und

Jugendmedizin, Universitätsklinikum Essen.

Address correspondence to Dr. D. Holzinger, Klinik für Kinderheilkunde III, Zentrum für Kinder- und Jugendmedizin, Universitätsklinikum

Essen, Hufelandstraße 55, 45147 Essen, Germany.

E-mail:Dirk.Holzinger@uk-essen.de

Accepted for publication September 22, 2017.

Juvenile idiopathic arthritis (JIA) is a clinically heterogeneous condition, frequently requiring therapy with conventional disease-modifying antirheumatic drugs (cDMARD) such as methotrexate (MTX). Combination therapy increasingly also includes biological DMARD (bDMARD) with antitumor necrosis factor (TNF) agents [e.g., etanercept (ETN) and adalimumab (ADA) $]^{1,2,3}$. However, up to $40 \%$, or even higher depending on the definition used, of patients will not respond to treatment with bDMARD ${ }^{4,5,6}$. Using biomarkers alongside known predictive demographic and clinical factors could help improve the prediction of response $e^{1,7,8}$.

S100A12 and myeloid-related protein complex 8/14 (MRP8/14 or S100A8/A9) are S100-protein family members. Both are calcium-binding proteins and phagocyte activation markers acting as proinflammatory ligands of Toll-like receptor-4, which are constitutively expressed predominantly in phagocytic myeloid cells (i.e., granulocytes and monocytes). It is thought that both proteins are secreted in a similar mechanism, either by nonclassical secretion from active cells or passively released from necrotic cells ${ }^{9}$. Both S100A12 and MRP8/14 are validated predictors of relapse risk and disease activity in JIA ${ }^{10,11,12}$. S100A12 concentration measured at the time of treatment withdrawal in patients with JIA predicted the development of flare better than MRP, with the combination of S100A12 plus high-sensitivity C-reactive protein performing best ${ }^{13}$. This suggests that differences exist in the performance of S100A12 and MRP8/14 as biomarkers, despite their many apparent similarities. Baseline MRP8/14 has already been shown to predict response to MTX and
anti-TNF treatment in patients with JIA. However, the association of serum S100A12 with response to therapy in JIA has not yet been evaluated ${ }^{14,15}$.

\section{MATERIALS AND METHODS}

Study population. Data were analyzed from 3 prospective cohort studies that were designed to study either the response to starting MTX or starting anti-TNF treatment (alone or in combination with other therapy including MTX; Table 1) in patients with JIA diagnosed according to the International League of Associations for Rheumatology (ILAR) criteria ${ }^{3}$. The study was open for patients with undifferentiated JIA, but no such patient was enrolled. The prediction of response by MRP8/14 in these cohorts has already been published in detail ${ }^{14,15}$, and here we focus on reporting the associations of S100A12. Response to MTX was analyzed using data from the UK Childhood Arthritis Response to Medication Study (CHARMS, 75 patients). Data on response to anti-TNF treatment were collected in the Dutch Arthritis and Biologicals in Children (ABC) Register $(n=68)$, the German Registry for Biologics in Paediatric Rheumatology (BIKeR, $n=12$ ), and the CHARMS $(n=8)$. Each of these studies recruited patients with all subtypes of JIA who

Table 1. Baseline demographics and characteristics of patients starting MTX and anti-TNF therapy.

\begin{tabular}{|c|c|c|}
\hline Baseline Demographic & $\begin{array}{l}\text { MTX-treated } \\
\text { Patients, } \mathrm{n}=75\end{array}$ & $\begin{array}{l}\text { Anti-TNF-treated } \\
\text { Patients, } \mathrm{n}=88\end{array}$ \\
\hline Age at JIA onset, yrs, median & $5.3(2.5-10.5)$ & $10.0(3.9-12.3)$ \\
\hline $\begin{array}{l}\text { Disease duration at therapy start, } \\
\text { yrs, median (IQR) }\end{array}$ & $1.4(0.5-3.8)$ & $2.3(0.9-6.0)$ \\
\hline Female, n $(\%)$ & $52(69)$ & $66(75)$ \\
\hline ANA-positive, $\mathrm{n} / \mathrm{N}(\%)$ & $48 / 72(67)$ & $25 / 76(33)$ \\
\hline RF-positive, $\mathrm{n} / \mathrm{N}(\%)$ & $10 / 71(14)$ & $13 / 80(16)$ \\
\hline \multicolumn{3}{|c|}{ JIA category at MTX or anti-TNF start, $\mathrm{n}(\%)$} \\
\hline Oligoarticular persistent & $13(17)$ & $5(6)$ \\
\hline Oligoarticular extended & $17(23)$ & $24(27)$ \\
\hline Polyarticular RF- & $29(39)$ & $33(38)$ \\
\hline Polyarticular RF+ & $6(8)$ & $13(15)$ \\
\hline Enthesitis-related arthritis & $6(8)$ & $4(5)$ \\
\hline Psoriatic & $3(4)$ & $9(10)$ \\
\hline Not available & $1(1)$ & 0 \\
\hline Undifferentiated & 0 & 0 \\
\hline \multicolumn{3}{|c|}{ Clinical variables at therapy start, median (IQR) } \\
\hline Physician's VAS $(0-100)$ & $38(22-56)$ & $54(30-68)$ \\
\hline Active joints, $\mathrm{n}$ & $5(2-8)$ & $10(5-17)$ \\
\hline Restricted joints, $\mathrm{n}$ & $3(2-6)$ & $6(2-14)$ \\
\hline Parent/patient VAS $(0-100)$ & $33(14-56)$ & $53(5-70)$ \\
\hline CHAQ score $(0-3)$ & $1.00(0.25-1.75)$ & $1.5(0.8-2.1)$ \\
\hline $\mathrm{ESR}, \mathrm{mm} / \mathrm{h}$ & $23(10-63)$ & $13(8-27)$ \\
\hline \multicolumn{3}{|l|}{ Concomitant therapy at therapy start } \\
\hline Methotrexate, n (\%) & $75(100)$ & $74(84)$ \\
\hline Anti-TNF therapy & 0 & $88(100)$ \\
\hline Systemic prednisolone, $\mathrm{n} / \mathrm{N}(\%)$ & $25 / 61(41)$ & $25 / 88(28)$ \\
\hline JADAS-10 (0-40), median (IQR) & $13(8-20)$ & $19(14-23)$ \\
\hline $\begin{array}{l}\text { S100A12 (in-house) at start in ng } \\
\text { median (IQR) }\end{array}$ & $\begin{array}{l}/ \mathrm{ml} \\
220(100-440)\end{array}$ & $200(133-440)$ \\
\hline \multicolumn{3}{|l|}{ S100A12 (CircuLex) at start in $\mathrm{ng} / \mathrm{ml}$, } \\
\hline median (IQR) & $605(318-1330)$ & $348(195-655)$ \\
\hline
\end{tabular}

MTX: methotrexate; anti-TNF: antitumor necrosis factor; JIA: juvenile idiopathic arthritis; IQR: interquartile range; ANA: antinuclear antibodies; RF: rheumatoid factor; VAS: visual analog scale; CHAQ: Childhood Assessment Questionnaire; ESR: erythrocyte sedimentation rate; JADAS-10: Juvenile Arthritis Disease Activity. 
fulfilled ILAR criteria and started either new DMARD or biologic therapy for active arthritis (CHARM). ABC and BIKeR cohort data were combined to increase statistical strength. MTX and anti-TNF therapies were prescribed at the dose according to the previously published study protocols ${ }^{4,6,14}$.

The BIKeR registry was approved by the ethics committee of the Ärztekammer Nordrhein Düsseldorf (ref 2/2015/7441). The CHARMS was approved by the Institute of Child Health/Great Ormond Street UK National Health Service Trust (MREC-05/Q0508/95), and the ABC Register was approved by the Medical Ethics Committee at Erasmus MC Rotterdam (MEC-225.804/2003/51). The BIKeR and ABC registries as well as the CHARMS included provision in their ethical approvals for the collection, storage, and analysis of biobanked samples. All 3 cohorts have been published in full elsewhere. Subjects were recruited with fully informed consent and child assent where appropriate ${ }^{4,6,14}$.

Definition of treatment response. Treatment responders achieved an American College of Rheumatology (ACR) Pediatric 50\% criteria for response (ACRpedi50) or better score at followup, equivalent to $\geq 50 \%$ improvement in a minimum of 3 out of 6 core variables, with no worsening in $>1$ remaining variable by $>30 \%$. Core variables are (1) physician's global assessment (PGA) score, using visual analog scale (VAS): range $0-10 \mathrm{~cm}$, $0=$ best score; (2) patient/parent global assessment of well-being (VAS: range $0-10 \mathrm{~cm}, 0=$ best score); (3) Childhood Health Assessment Questionnaire (CHAQ, range $0-3,0=$ best score); (4) number of joints with active arthritis; (5) number of joints with limited motion; and (6) erythrocyte sedimentation rate $(\mathrm{ESR})^{3,16}$. Disease activity and response were also quantified by parent/patient pain VAS, the achievement of inactive disease and change in Juvenile Arthritis Disease Activity Score (JADAS)-10, defined as the difference between baseline and followup JADAS-10 ${ }^{17}$. The JADAS-10 score is quantified in 4 domains, 3 on a continuous scale (PGA, parent/patient global, and no. active joints out of 10 specified), and the fourth being the presence of a normalized ESR ${ }^{18}$. The modified definition of inactive disease (ID; Wallace, et al $^{19}$ ) requires the absence of active arthritis, systemic features, uveitis, and normal ESR $(\leq 20 \mathrm{~mm} / \mathrm{h})$, but accepts a higher acceptable PGA of $\leq 1.0 \mathrm{~cm}$ (which in practice is rarely scored as 0 ), compared to the standard ID definition. Because all patients achieving ID also fulfill ACR50, ACR50 was used as the measure of response; if any prediction of response was found with this lower threshold, it is likely the same, or a higher response would be present with the use of ID. Baseline demographics and clinical scores including JADAS-10 are shown in Table 1 , and the followup characteristics (responders and nonresponders) are shown in Supplementary Table 1 (available with the online version of this article).

S100A12 measurement. Serum concentrations were measured using a well-described in-house ELISA assay as well as a commercial assay (CircuLex, CycLex Co. Ltd) on frozen samples ${ }^{11,13}$. Both assays were used to investigate whether measured concentrations were reproducible in both, and to identify a suitable commercial assay approved for research use in further studies, which do not have access to this in-house ELISA. Reference internal control sera were used in each assay. S100A12 is a stable biomarker that is reliably measurable in samples sent at room temperature as well as in repeatedly thawed and frozen samples. All reported S100A12 values refer to in-house assay results unless specified. Results using the commercial assay are shown in Supplementary Tables 2 and 3 (available with the online version of this article). All assays were performed blind to the clinical diagnosis and results were not reported to treating clinical staff during the study. Results are presented as median (interquartile range; IQR).

Statistical analysis. Categorical characteristics were tested using the chi-square test, continuous variables with the Mann-Whitney U test, and correlations with the Spearman (rs) or Pearson (r) test. Baseline and followup S100A12 were compared in paired analyses using the Wilcoxon signed-rank test. Baseline S100A12 concentration was assessed for its prediction of ACRpedi outcome by binary logistic regression modeling and association with change in JADAS-10 by linear regression modeling. Multivariable linear models were also fitted for change in JADAS-10, allowing correction for other potential predictors and to assess the added value of S100A12 in predicting response. For this modeling, known predictive variables (sex, age at JIA onset, disease duration, baseline JADAS-10, baseline CHAQ, no. previously used DMARD, and ESR) were prespecified ${ }^{7,8,20,21}$. Missing data were handled using the chained equations multiple imputation command ice in Stata/SE (v13.0). Patients treated with anti-TNF (ADA or ETN) were combined after being assessed as having identical characteristics. Cutoff values for baseline S100A12 as a predictive marker for treatment response were defined using receiver-operator characteristic (ROC) analysis ${ }^{13}$. Other analyses were performed with SPSS (IBM for Windows V.21) and Prism (Graphpad v5).

Table 2. Association of response to therapy to baseline S100A12 concentration.

\begin{tabular}{|c|c|c|}
\hline Logistic regression: predicted minimum ACRpedi50 response & Unadjusted OR (95\% CI) & $\mathrm{p}$ \\
\hline \multicolumn{3}{|l|}{ MTX therapy } \\
\hline S100A12, per 50 -unit $\mathrm{ng} / \mathrm{ml}$ increase & $1.213(1.01-1.45)$ & 0.034 \\
\hline \multicolumn{3}{|l|}{ Anti-TNF therapy } \\
\hline S100A12, per 50-unit $\mathrm{ng} / \mathrm{ml}$ increase & $1.04(1.01-1.08)$ & 0.014 \\
\hline Univariate linear regression: predicted change in JADAS- 10 & $\beta(95 \% \mathrm{CI})$ & $\mathrm{p}$ \\
\hline \multicolumn{3}{|l|}{ MTX therapy } \\
\hline S100A12, per 50-unit $\mathrm{ng} / \mathrm{ml}$ increase & $-0.453(-0.726$ to -0.181$)$ & 0.002 \\
\hline \multicolumn{3}{|l|}{ Anti-TNF therapy } \\
\hline $\mathrm{S} 100 \mathrm{~A} 12$, per 50 -unit $\mathrm{ng} / \mathrm{ml}$ increase & $0.064(0.025-0.102)$ & 0.001 \\
\hline Multivariate linear regression: predicted change in JADAS-10 & $\beta(95 \% \mathrm{CI})$ & $\mathrm{p}$ \\
\hline \multicolumn{3}{|l|}{ MTX therapy } \\
\hline S100A12, per 50-unit $\mathrm{ng} / \mathrm{ml}$ increase & $0.197(-0.397$ to 0.003$)$ & ns \\
\hline \multicolumn{3}{|l|}{ Anti-TNF therapy } \\
\hline $\mathrm{S} 100 \mathrm{~A} 12$, per 50 -unit $\mathrm{ng} / \mathrm{ml}$ increase & $0.045(0.015-0.076)$ & 0.004 \\
\hline
\end{tabular}

ACRpedi50: American College of Rheumatology Pediatric 50\% criteria for response; MTX: methotrexate; anti-TNF: antitumor necrosis factor; JADAS-10: Juvenile Arthritis Disease Activity Score; ns: nonsignificant. 
Table 3. Sensitivity, specificity, and likelihood ratios for the determined cutoff of S100A12 predicting response to MTX and anti-TNF therapy.

\begin{tabular}{lcc}
\hline Accuracy Measure & MTX Therapy & Anti-TNF Therapy \\
\hline Cutoff level S100A12, ng/ml & 260 & 213 \\
Sensitivity & 47.4 & 58.6 \\
Specificity & 88.9 & 80.7 \\
Positive likelihood ratio & 4.3 & 3.0 \\
Negative likelihood ratio & 1.7 & 0.5 \\
Youden index & 0.363 & 0.392 \\
AUC (95\% CI) & $0.675(0.559-0.805)$ & $0.734(0.622-0.846)$ \\
\hline
\end{tabular}

AUC: area under the curve; MTX: methotrexate; anti-TNF: antitumor necrosis factor.

\section{RESULTS}

Baseline characteristics. Baseline median S100A12 concentration in patients before either therapy (MTX: $n=75$, anti-TNF: $\mathrm{n}=88$ ) significantly correlated with baseline ESR (MTX rs 0.40, p < 0.001; anti-TNF rs 0.38, p < 0.001) and JADAS-10 (MTX rs 0.25, p =0.04; anti-TNF rs 0.22, $\mathrm{p}=0.04$; Table 1). Subgroup analysis of S100A12 with number of active joints at start showed no correlation (Spearman's $\rho 0.19, \mathrm{p}=0.072$ ). In MTX-treated patients, there was no difference in baseline S100A12 among JIA subtypes ( $\mathrm{p}=0.17$, Kruskal-Wallis test). However, in patients treated with anti-TNF, a difference among patients of different subtypes was seen $(p=0.024)$, with the highest concentrations in polyarticular rheumatoid factor-positive JIA (median $411 \mathrm{ng} / \mathrm{ml}, \mathrm{n}=13$ ) and the lowest in oligoarticular-persistent JIA (median $56 \mathrm{ng} / \mathrm{ml}, \mathrm{n}=5$ ).

Clinical response to therapy. Followup was at a median of 6.6 months (IQR 5.8-7.6) for MTX and 3.2 (2.6-5.0) months for patients treated with anti-TNF. The clinical response of each treatment group was analyzed separately, therefore this difference did not affect the results shown. Based on achievement of ACRpedi50 or better at followup, 57 of 75 MTX-treated patients and 66 of 88 anti-TNF patients were responders. Of the 66 anti-TNF responders, 46 had an ACRpedi70 or better response, while 31 were in clinical remission. The modified criteria for ID were fulfilled by 25/75 of MTX and 31/88 of patients treated with anti-TNF. JADAS-10 at followup was median 3 (IQR 1-8) for MTX-treated and 4 (1-9) for anti-TNF-treated patients (Supplementary Table 1, available with the online version of this article), improving from baseline (Table 1). There were no significant differences between responders and nonresponders for either treatment group in baseline disease characteristics, excluding the variables included in the ID and JADAS-10 score (Supplementary Table 1).

Baseline S100A12 and response to therapy. Baseline S100A12 concentration was higher in responders versus nonresponders [Figure 1A, MTX median 240 (IQR 125-615) $\mathrm{ng} / \mathrm{ml}$ vs $150(87-233) \mathrm{ng} / \mathrm{ml}, \mathrm{p}=0.02$; Figure $1 \mathrm{~B}$, anti-TNF median 308 (IQR 150-624) ng/ml vs 151 (IQR 83-201) $\mathrm{ng} / \mathrm{ml}, \mathrm{p}=0.002]$. Increased baseline S100A12 was associated with OR $>1$ for the prediction of ACRpedi50 and improvement in JADAS-10 in univariate models at followup, for both treatments (Table 2). For patients using anti-TNF and MTX therapy, logistic regression modeling was also performed with the additional variable "MTX at start" and the OR for baseline S100A12 did not change, and concomitant MTX was not a significant factor in the combined model (OR 3.46, 95\% CI 0.93-12.85). Multivariate models constructed with known predictors of response, as detailed in the statistical methods above, tested their prediction of JADAS-10. Excluding S100A12, model variables explained $70 \%$ of the variance in change in JADAS-10 at followup for MTX-treated patients and $50 \%$ of the variance for the anti-TNF group. Including S100A12 as a variable improved the predictive models by $2 \%$ (not significant) for MTX and $5 \%(\mathrm{p}=0.004)$ for anti-TNF therapy (Table 2$)$.

Followup S100A12. Followup S100A12 concentrations were determined for MTX (44/75) and anti-TNF (39/88) patients, limited only by lack of serum for this analysis, which was performed blinded. Of these, 34/44 (77\%) of MTX and 26/39 (67\%) of anti-TNF patients were responders. At followup, both responders and nonresponders, irrespective of therapy, had comparable S100A12 concentrations: MTX responders median 165 (IQR 113-273), nonresponders 79 (46-213, $\mathrm{p}=0.08)$; anti-TNF treatment responders median 110 (53-254), nonresponders 91 (42-235, p = 0.55; Figure 1). However, responders (those achieving ACRpedi50) had significant reduction from their baseline S100A12 concentration measured by the Wilcoxon signed-rank test (Supplementary Table 1, available with the online version of this article). Sensitivity, specificity, and likelihood ratios for prediction of response by S100A12 using ROC analysis are shown in Table 3.

Use of concomitant therapy. Concomitant therapy was given according to physician choice. The percentage of patients using concomitant MTX at the start of anti-TNF therapy in the group of responders was $91 \%(60 / 66)$ and in the nonresponders, $63 \%$ (14/22). Systemic corticosteroid use at the start of MTX treatment $(n=25 / 61,41 \%)$ was not associated with any significant differences in either baseline or followup S100A12. However, in the anti-TNF treatment group, those who were also receiving corticosteroids at the start of the treatment $(n=25 / 88)$ had higher baseline S100A12 than those who did not (median 380, IQR $177-838 \mathrm{ng} / \mathrm{ml}$ vs 187 , IQR $128-331 \mathrm{ng} / \mathrm{ml}, \mathrm{p}=0.006)$ and also greater change at followup $[\Delta \mathrm{S} 100 \mathrm{~A} 12-145(-327$ to -97$)$ vs $-84(-149$ to $13), \mathrm{p}=0.034]$. However, there was no difference in corticosteroid use between patients characterized as responders or nonresponders, therefore concomitant corticosteroid use was unlikely to be the major factor in patients reaching clinical response. So few patients used concomitant DMARD (excluding MTX; MTX-treated = 3/66; anti-TNF-treated $=3 / 88$ ) that no conclusions could be drawn.

Personal non-commercial use only. The Journal of Rheumatology Copyright $\odot$ 2018. All rights reserved 


\section{Baseline}

A

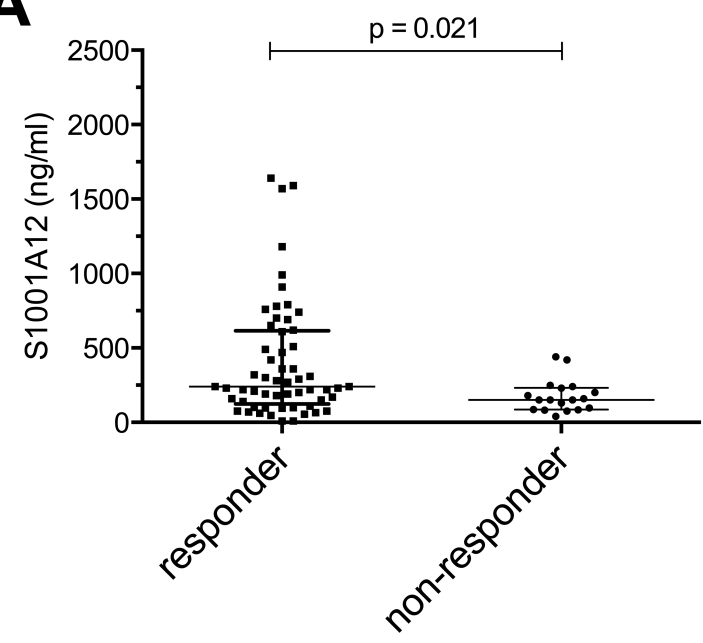

B

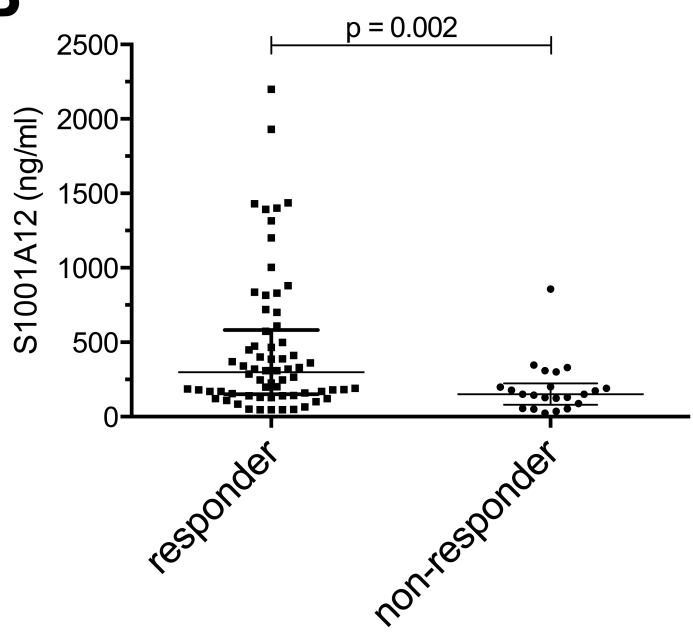

Follow-up: responders

C

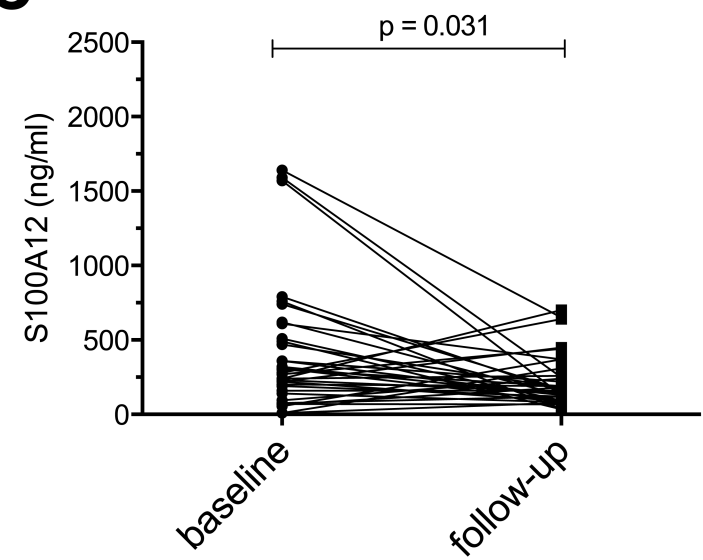

D

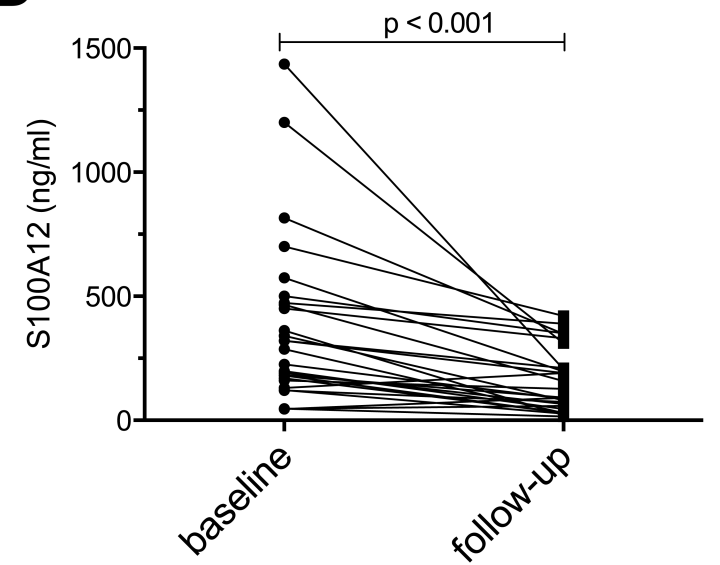

Follow-up: non-responders

E

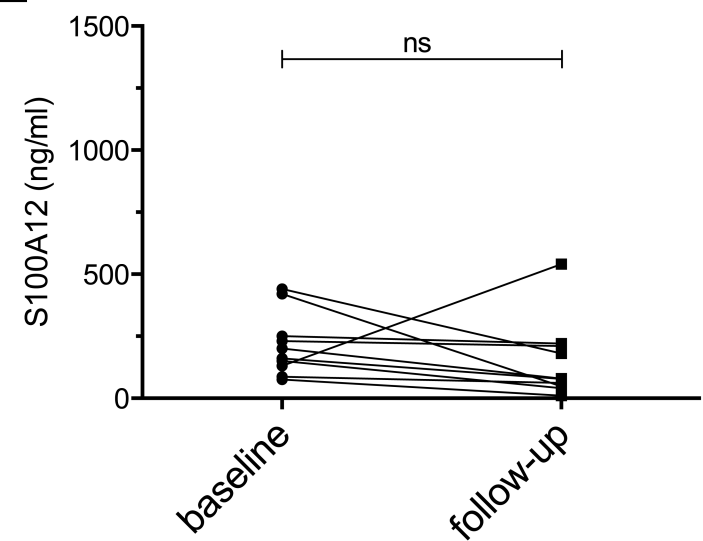

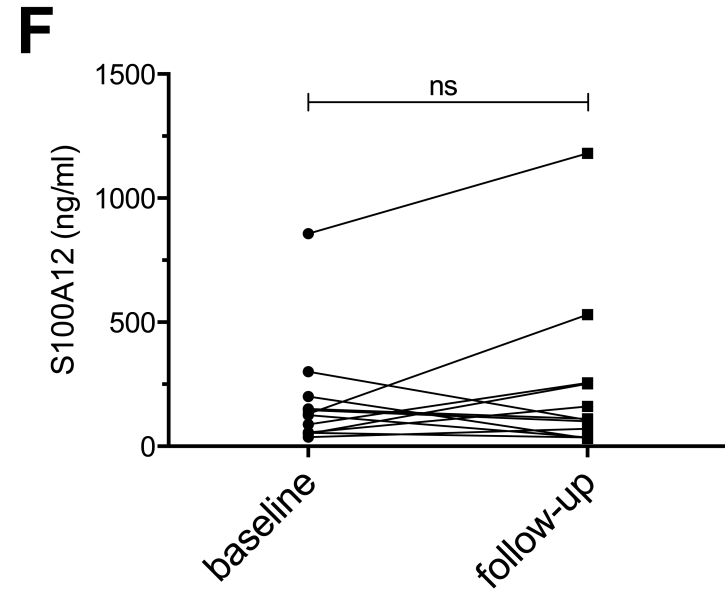

Figure 1. Baseline and followup S100A12 concentration by therapy used. Differences in baseline S100A12 concentrations in responders and nonresponders to MTX (A) or anti-TNF therapy (B) measured by the in-house ELISA are shown. Change in S100A12 concentration after treatment with MTX and anti-TNF therapy is shown for responders $(\mathrm{C}-\mathrm{D})$ and nonresponders $(\mathrm{E}-\mathrm{F})$. Horizontal bars indicate the median concentration and vertical bars the interquartile range. MTX: methotrexate; anti-TNF: antitumor necrosis factor.

\section{Personal non-commercial use only. The Journal of Rheumatology Copyright (c) 2018. All rights reserved.}


Measurement of S100A12 by commercial ELISA. S100A12 measured by commercial assay (Supplementary Table 2, available with the online version of this article) was comparable with in-house assay results and also showed significantly higher S100A12 in responders versus nonresponders and higher baseline versus followup concentrations. However, while a good area under the curve (AUC) was obtained for both therapy groups, it was lower with the commercial (MTX AUC 0.662, 95\% CI 0.532-0.791; anti-TNF $0.675,95 \%$ CI $0.550-0.800$ ) versus in-house assay (MTX AUC 0.675, 95\% CI 0.559-0.805; anti-TNF 0.734, 95\% CI 0.662-0.846). Sensitivity (commercial ELISA: MTX 45.6, anti-TNF 39.4; in-house ELISA: MTX 47.4, anti-TNF 58.6) and specificity (commercial ELISA: MTX 83.3, anti-TNF 86.4; in-house ELISA: MTX 88.9, anti-TNF 80.7) were also lower with the commercial ELISA. Absolute commercial assay concentrations were also higher than the in-house assay, about double, and the cutoff levels calculated for each therapy group were also much wider than with the in-house assay.

\section{DISCUSSION}

Baseline serum S100A12 was associated with response to both MTX and anti-TNF therapy in patients with JIA who had a high baseline concentration that decreased significantly with either MTX or anti-TNF treatment. Patients with higher baseline S100A12 concentration had higher disease activity and ESR, and were more likely to be treatment responders. Further, the addition of S100A12 to multivariate models improved the prediction of response.

The aim of our study was not to directly compare level of response to MTX versus anti-TNF therapy, or to consider their combined therapy versus individual use, but rather to determine whether S100A12 concentration can predict a response to therapy when a clinician initiates either of these medications. Further work and specific trials are needed to determine which therapy would be best initiated in which patients, and such studies would also require the availability of predictive markers of response, such as S100A12, which is discussed here.

S100A12 has already been shown to correlate with disease activity, and concentrations $>175 \mathrm{ng} / \mathrm{ml}$ potentially predict increased risk of flare in patients who have had treatment withdrawn ${ }^{10,13,22,23,24}$. The followup time of patients in our study was a median of 5 months. Most patients would be expected to show a treatment response within 3 months after initiation, with S100 concentrations shown to decrease in response to effective biological treatment within 4 weeks ${ }^{25,26}$.

Moncrieffe, et al and Anink, et al identified MRP8/14 as being associated with response to MTX and anti-TNF therapy, and also suggested predictive modeling could be improved by including additional variables ${ }^{14,15}$. S100A12, like MRP8/14, has the advantage over other cytokines, e.g., interleukin $1 \beta$, in having greater temperature stability, even withstanding storage and being mailed at room temperature. S100A12 measurement could therefore feasibly be incorporated into the routine laboratory examinations for JIA and also be incorporated into treatment prediction models $\mathrm{s}^{7,21,27,28}$.

While a well-established experimental ELISA S100A12 protocol exists, it is not yet in routine use. The commercial ELISA has already been demonstrated to perform well in analyzing patient serum ${ }^{11,29}$. Both assays require serial dilution of serum to obtain reliable results, owing to the wide range of S100A12 concentrations among patients ${ }^{11}$. Therefore, while either assay can be used, results from each should not be directly compared and used only with assay-specific cutoffs. Although overall the same pattern of results was obtained with both assays, the in-house ELISA performed marginally better, as reflected by the slightly higher AUC and Youden Index values achieved for both MTX and anti-TNF treatment groups with the in-house assay compared to those of the commercial assay.

Whereas S100A12 and MRP8/14 have reported some similarities in intra- and extracellular functions, the mechanism of release for each remains unknown. There are clear differences in the expression and functions between the 2 proteins $^{9}$. A hallmark of MRP8/14 is its formation of a heterodimer, while the hexamer is thought to be the active extracellular form of S100A12 ${ }^{30}$. Adding S100A12 into the multivariable models (investigated for MRP8/14 by Moncrieffe, et al) did result in a further increase in explained variance, though only a relatively small percentage $(2 \%$, nonsignificant) for MTX, but 5\% ( $\mathrm{p}<0.005)$ for the anti-TNF group ${ }^{14}$.

In this cohort, baseline ESR and number of active joints already differentiated well those patients who later became responders from nonresponders, which could be one reason the addition of S100A12 to a multimarker model added limited benefit. Other cohorts, particularly larger clinical cohorts, are required to ascertain whether S100A12 is a clinically useful predictive marker.

It is likely that no single biomarker can be sufficiently sensitive or specific for predicting response, and multimarker panels are increasingly being sought, such as the multibiomarker disease activity test for rheumatoid arthritis ${ }^{1,31}$. It is also important to acknowledge that there is, to date, a lack of clinically viable alternative biomarkers that could replace S100A12 or MRP8/14, or add to their prediction in such multivariable models. Additionally, heterogeneity within the same subgroup of JIA could be a further factor in variation in treatment response, and would further support the use of multimarker panels to individualize management strategies. Small cohort size also increases the chance of clinical heterogeneity leading to statistically significant outcomes, and we combined 2 cohorts for the anti-TNF group to counter this. Larger studies would require greater multicenter collaboration and the use of inception cohorts. One factor that could

Personal non-commercial use only. The Journal of Rheumatology Copyright $@$ 2018. All rights reserved 
be investigated is the presence and influence of TNF- $\alpha$ gene polymorphisms, which could be associated with the heterogeneity of response to anti-TNF treatment ${ }^{32}$.

Biological and MTX therapies are associated with potentially significant adverse effects, and are expensive $e^{3,25,33}$. Most importantly, around a third of patients will show poor response to therapy $y^{4,5,6,7}$. In our study, the initiation of both MTX and anti-TNF treatment was effective and was associated with improvements in clinical disease activity measures, JADAS-10 score, attainment of ID, and ACRpedi50 responses. Because of limitations in the size of the dataset, we could not perform further subgroup analyses of response by each ACRpedi level, and instead used ACRpedi50 or better as the cutoff, using information from the JADAS score to supplement the measure of clinical improvement. Over $50 \%$ of patients in each group reached an ACRpedi50 or better response, in line with published literature, including the study of ETN efficacy by Quartier, et al, in which over half of treated patients with JIA had over a minimum 50\% improvement in their core set criteria at 3 months ${ }^{25}$. Alongside the baseline characteristics, this result suggested that our patient population was an average group ${ }^{34}$. However, the effect of concomitant therapy use by patients (MTX plus anti-TNF therapy and/or other therapies such as corticosteroids) should be investigated specifically in more detail.

We have shown that high pretreatment S100A12 serum concentrations of patients with JIA are associated with a good response to MTX or anti-TNF therapy. Further work should be done to identify the ideal clinical scenarios in which this biomarker could best be used (at onset of treatment in the absence of corticosteroid treatment, for example, or limited to anti-TNF- treated patients, or to predict patients who will respond to one drug rather than another, or in combined therapies from the outset). In addition, this work highlights that there is a significant clinical need for the clinical evaluation of predictive biomarkers. However, to achieve these objectives, validation cohorts with frequent longitudinal followup are required.

\section{ACKNOWLEDGMENT}

The authors thank all the patients and their families for participating in the included studies, the ward and clinical staff for help collecting samples and data, and laboratory teams for sample handling and processing, as well as each member of the study groups (Childhood Arthritis Response to Medication Study, CHARMS; Arthritis and Biologicals in Children, ABC Register; and the Biologics in Paediatric Rheumatology, BIKeR Registry). We especially thank M. Saers and S. Schleifenbaum for excellent technical assistance.

\section{ONLINE SUPPLEMENT}

Supplementary material accompanies the online version of this article.

\section{REFERENCES}

1. Hinze C, Gohar F, Foell D. Management of juvenile idiopathic arthritis: hitting the target. Nat Rev Rheumatol 2015;11:290-300.

2. Beukelman T, Patkar NM, Saag KG, Tolleson-Rinehart S, Cron RQ, DeWitt EM, et al. 2011 American College of Rheumatology recommendations for the treatment of juvenile idiopathic arthritis: initiation and safety monitoring of therapeutic agents for the treatment of arthritis and systemic features. Arthritis Care Res 2011;63:465-82.

3. Ringold S, Weiss PF, Beukelman T, DeWitt EM, Ilowite NT, Kimura Y, et al. 2013 update of the 2011 American College of Rheumatology recommendations for the treatment of juvenile idiopathic arthritis. Arthritis Rheum 2013;65:2499-512.

4. Horneff G, Schmeling H, Biedermann T, Foeldvari I, Ganser G, Girschick HJ, et al. The German etanercept registry for treatment of juvenile idiopathic arthritis. Ann Rheum Dis 2004;63:1638-44.

5. Lovell DJ, Reiff A, Ilowite NT, Wallace CA, Chon Y, Lin SL, et al. Safety and efficacy of up to eight years of continuous etanercept therapy in patients with juvenile rheumatoid arthritis. Arthritis Rheum 2008;58:1496-504.

6. Prince FH, Twilt M, ten Cate R, van Rossum MA, Armbrust W, Hoppenreijs EP, et al. Long-term follow-up on effectiveness and safety of etanercept in juvenile idiopathic arthritis: the Dutch national register. Ann Rheum Dis 2009;68:635-41.

7. Otten MH, Prince FH, Armbrust W, ten Cate R, Hoppenreijs EP, Twilt M, et al. Factors associated with treatment response to etanercept in juvenile idiopathic arthritis. JAMA 2011; 306:2340-7.

8. Geikowski T, Becker I, Horneff G. Predictors of response to etanercept in polyarticular-course juvenile idiopathic arthritis. Rheumatology 2014;53:1245-9.

9. Kessel C, Holzinger D, Foell D. Phagocyte-derived S100 proteins in autoinflammation: putative role in pathogenesis and usefulness as biomarkers. Clin Immunol 2013;147:229-41.

10. Holzinger D, Frosch M, Kastrup A, Prince FH, Otten MH, Van Suijlekom-Smit LW, et al. The Toll-like receptor 4 agonist MRP8/14 protein complex is a sensitive indicator for disease activity and predicts relapses in systemic-onset juvenile idiopathic arthritis. Ann Rheum Dis 2012;71:974-80.

11. Rothmund F, Gerss J, Ruperto N, Däbritz J, Wittkowski H, Frosch $\mathrm{M}$, et al. Validation of relapse risk biomarkers for routine use in patients with juvenile idiopathic arthritis. Arthritis Care Res 2013;66:949-55.

12. Foell D, Wulffraat N, Wedderburn LR, Wittkowski H, Frosch M, Gerss J, et al. Methotrexate withdrawal at 6 vs 12 months in juvenile idiopathic arthritis in remission: a randomized clinical trial. JAMA 2010;303:1266-73.

13. Gerss J, Roth J, Holzinger D, Ruperto N, Wittkowski H, Frosch M, et al. Phagocyte-specific S100 proteins and high-sensitivity C reactive protein as biomarkers for a risk-adapted treatment to maintain remission in juvenile idiopathic arthritis: a comparative study. Ann Rheum Dis 2012;71:1991-7.

14. Moncrieffe H, Ursu S, Holzinger D, Patrick F, Kassoumeri L, Wade A, et al. A subgroup of juvenile idiopathic arthritis patients who respond well to methotrexate are identified by the serum biomarker MRP8/14 protein. Rheumatology 2013;52:1467-76.

15. Anink J, Van Suijlekom-Smit LW, Otten MH, Prince FH, van Rossum MA, Dolman KM, et al. MRP8/14 serum levels as a predictor of response to starting and stopping anti-TNF treatment in juvenile idiopathic arthritis. Arthritis Res Ther 2015;17:200.

16. Giannini EH, Ruperto N, Ravelli A, Lovell DJ, Felson DT, Martini A. Preliminary definition of improvement in juvenile arthritis. Arthritis Rheum 1997;40:1202-9.

17. Horneff G, Becker I. Definition of improvement in juvenile idiopathic arthritis using the juvenile arthritis disease activity score. Rheumatology 2014;53:1229-34.

18. Consolaro A, Ruperto N, Bazso A, Pistorio A, Magni-Manzoni S, Filocamo G, et al. Development and validation of a composite disease activity score for juvenile idiopathic arthritis. Arthritis Rheum 2009;61:658-66.

Personal non-commercial use only. The Journal of Rheumatology Copyright $\subset$ 2018. All rights reserved. 
19. Wallace CA, Giannini EH, Huang B, Itert L, Ruperto N. American College of Rheumatology provisional criteria for defining clinical inactive disease in select categories of juvenile idiopathic arthritis. Arthritis Care Res 2011;63:929-36.

20. Solari N, Palmisani E, Consolaro A, Pistorio A, Viola S, Buoncompagni A, et al. Factors associated with achievement of inactive disease in children with juvenile idiopathic arthritis treated with etanercept. J Rheumatol 2013;40:192-200.

21. Bulatovic M, Heijstek MW, Van Dijkhuizen EH, Wulffraat NM, Pluijm SM, de Jonge R. Prediction of clinical non-response to methotrexate treatment in juvenile idiopathic arthritis. Ann Rheum Dis 2012;71:1484-9.

22. Bae CB, Suh CH, An JM, Jung JY, Jeon JY, Nam JY, et al. Serum S100A12 may be a useful biomarker of disease activity in adult-onset Still's disease. J Rheumatol 2014;41:2403-8.

23. Yamasaki Y, Takei S, Imanaka H, Nerome Y, Kubota T, Nonaka Y, et al. Prediction of long-term remission of oligo/polyarticular juvenile idiopathic arthritis with S100A12 and vascular endothelial growth factor. Mod Rheumatol 2016;26:551-6.

24. Rahman MT, Myles A, Gaur P, Misra R, Aggarwal A. TLR4 endogenous ligand MRP8/14 level in enthesitis-related arthritis and its association with disease activity and TLR4 expression. Rheumatology 2014;53:270-4.

25. Quartier P, Taupin P, Bourdeaut F, Lemelle I, Pillet P, Bost M, et al. Efficacy of etanercept for the treatment of juvenile idiopathic arthritis according to the onset type. Arthritis Rheum 2003; 48:1093-101

26. Choi IY, Gerlag DM, Herenius MJ, Thurlings RM, Wijbrandts CA, Foell D, et al. MRP8/14 serum levels as a strong predictor of response to biological treatments in patients with rheumatoid arthritis. Ann Rheum Dis 2015;74:499-505.
27. Pomirleanu C, Ancuta C, Miu S, Chirieac R. A predictive model for remission and low disease activity in patients with established rheumatoid arthritis receiving TNF blockers. Clin Rheumatol 2013;32:665-70

28. Marotte H, Miossec P. Biomarkers for prediction of TNFalpha blockers response in rheumatoid arthritis. Joint Bone Spine 2010;77:297-305.

29. CircuLex S100A12/EN-RAGE ELISA Kit Ver.2. MBL Life Science [Internet. Accessed November 8, 2017.] Available from: http://ruo.mbl.co.jp/bio/g/dtl/P/?pcd=CY-8058V2\#u-pub

30. Kessel C, Fühner S, Brockmeyer S, Wittkowski H, Föll D. Hexameric S100A12 is required for pro-inflammatory TLR4-signalling [abstract OP0194]. Ann Rheum Dis 2015;74 Suppl 2:144-5.

31. Centola M, Cavet G, Shen Y, Ramanujan S, Knowlton N, Swan KA, et al. Development of a multi-biomarker disease activity test for rheumatoid arthritis. PLoS One 2013;8:e60635.

32. Scardapane A, Ferrante R, Nozzi M, Savino A, Antonucci I, Dadorante V, et al. TNF-alpha gene polymorphisms and juvenile idiopathic arthritis: Influence on disease outcome and therapeutic response. Semin Arthritis Rheum 2015;45:35-41.

33. Tynjälä $\mathrm{P}$, Vähäsalo $\mathrm{P}$, Tarkiainen $\mathrm{M}$, Kröger L, Aalto K, Malin M, et al. Aggressive combination drug therapy in very early polyarticular juvenile idiopathic arthritis (ACUTE-JIA): a multicentre randomised open-label clinical trial. Ann Rheum Dis 2011;70:1605-12.

34. van Riel PL, Taggart AJ, Sany J, Gaubitz M, Nab HW, Pedersen R, et al. Efficacy and safety of combination etanercept and methotrexate versus etanercept alone in patients with rheumatoid arthritis with an inadequate response to methotrexate: the ADORE study. Ann Rheum Dis 2006;65:1478-83. 